\title{
Update on Thyroid Nodule Management
}

\author{
Alan A Parsa ${ }^{1}$ and Hossein Gharib² \\ 1. University of Hawaii, John A Burns School of Medicine, Honolulu, Hawaii, USA; 2. Mayo Clinic College of Medicine, Division of Endocrinology, \\ Diabetes, Metabolism \& Nutrition, Mayo Clinic Rochester, Minnesota, USA
}

$\mathrm{O}$ ver time, we have seen an increase in the detection of thyroid nodules; much of this can be attributed to the increased use of sensitive imaging modalities for unrelated conditions that capture the neck and thyroid region. Due diligence has led to an increased incidence of thyroid cancer, followed by surgical intervention and radioactive ablation; much of which may be unwarranted or overly aggressive. Here we describe newer classifications designed to identify and stratify thyroid nodule risks, offering a strategy of separating high-risk from low-risk nodules and outlining ways to monitor thyroid nodules.

\section{Keywords}

Thyroid, thyroid nodule, thyroid ultrasound, thyroid malignancy, thyroid cytopathology, thyroid evaluation, thyroid pathology, thyroid cancer

Disclosures: Alan A Parsa and Hossein Gharib have no conflicts of interest to declare in relation to this article.

Review Process: Double-blind peer review.

Compliance with Ethics: This article involves a review of literature and does not report on new clinical data, or any studies with human or animal subjects performed by any of the authors.

Authorship: All named authors meet the criteria of the International Committee of Medical Journal Editors for authorship for this manuscript, take responsibility for the integrity of the work as a whole and have given final approval for the version to be published.

Received: November 27, 2018

Accepted: December 6, 2018

Citation: US Endocrinology. 2019;15(1):32-8

Corresponding Author: Alan A Parsa, 1329 Lusitana st. \#807 Honolulu, Hawaii, 96813, USA. E: aparsa@hawaii.edu

Support: No funding was received in

the publication of this article.
Palpation and physical exam remain an important part of thyroid evaluation, and while nodular discovery has increased overall, the prevalence of palpable thyroid nodules has not changed significantly since the 1960s, and remains around 3-7\%. ${ }^{1-5}$ Currently, ultrasonography of the neck area has incidentally identified thyroid nodules with an incidence of 30-70 \%, ${ }^{6,7}$ and unrelated computerized tomography (CT) scans containing the neck have increased thyroid nodule identification in 16-18\% of patients. ${ }^{8-10}$ It is has been estimated that in $2018,54,000$ new cases of thyroid malignancy will be diagnosed with around 2,000 deaths related to thyroid cancer. ${ }^{11}$ This estimates to around $0.3 \%$ of thyroid cancer related deaths, and $3.1 \%$ of all cancer related deaths for 2018 as recorded by the National Cancer Institute ( $\mathrm{NCl}$ ), a branch of the National institute of Health $(\mathrm{NIH})$, at the time this manuscript was written. ${ }^{12}$

With increased detection of nodules and lack of consistent assessment protocols, surgery has been a favored treatment modality for both malignant and benign nodules. While this removes the tumor burden, in many cases surgery can lead to surgically associated complications, life-long thyroxine therapy for the patient, an increased overall cost burden with minimal to no changes in survival rates, in small localized or benign lesions. ${ }^{11}$ Over the years, our understanding of thyroid nodules and the natural progression of thyroid cancer has been a guiding force leading to a more standardized evaluation and management. In this article, we review recommendations of how to evaluate and manage thyroid nodules, from the initial ultrasound, to biopsy, to molecular testing.

\section{Evaluation of nodules via imaging}

The value of ultrasound to evaluate a thyroid nodule has improved over time, not only in resolution but also in identifying specific features associated with a higher risk of malignancy. Unfortunately, inconsistent or incomplete reporting, and interobserver variability, may lead to inappropriate or overaggressive management. A recent retrospective analysis was highly suggestive that the vast majority of current radiological reports provide insufficient information to allow the clinician to effectively risk stratify nodules. ${ }^{13}$ It has been a goal of various societies to develop a platform for uniform reporting. While each society differs in their reporting method, similarities are evident in determining risk of malignancy (e.g., size, shape, echogenicity, calcifications, and vascularity). Reports comparing three societies (American Association of Clinical Endocrinologists [AACE]/Associazione Medici Endocrinologi [AME], American Thyroid Association [ATA], American College of Radiology [ACR]) suggest a similar predictive accuracy in determining risk of malignancy. ${ }^{14-16}$ Thus, until evidence suggests a clear benefit from one reporting system over another, it is up to the center performing the evaluations to determine which reporting system is most suitable for them, and to maintain a reporting consistency for practitioner review. 
Figure 1: Some of the ultrasonic features used to describe thyroid nodules
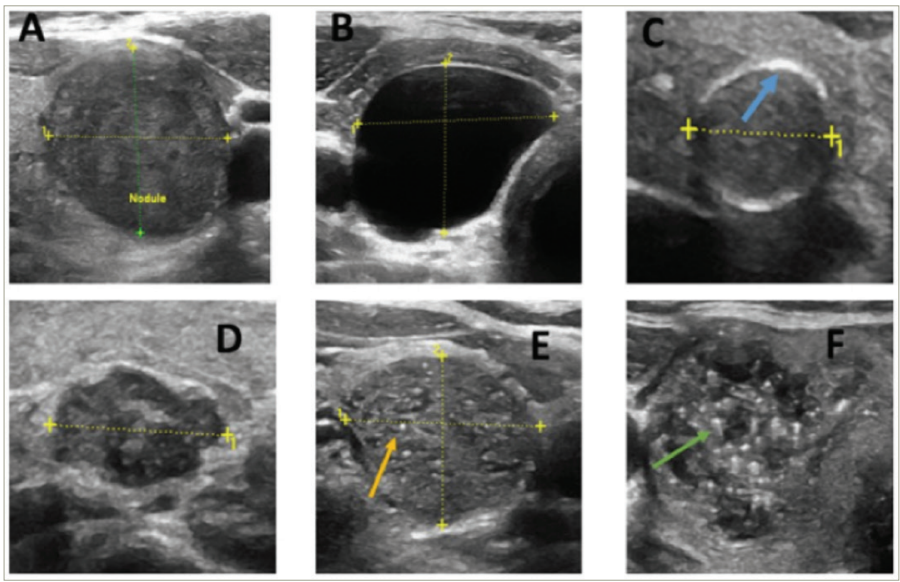

A. hypoechoic nodule; $B$. anechoic or cystic nodule; C. a nodule possessing rim calcification (blue arrow); D. nodule with jagged or irregular borders; E. microcalcifications (orange arrow); F. coarse calcifications with acoustic shadowing, also know as comet tails (green arrow).

\section{Important ultrasonographic features identified by each society Echogenicity}

The reflective comparison of a nodule to its surrounding normal thyroid tissue determines its echogenicity. For example, a hypoechogenic nodule (Figure 1) is darker than the surrounding normal thyroid tissue, while a hyperechogenic nodule is brighter than the surrounding thyroid tissue. A marked hypoechogenic nodule is even darker and compares the nodule echogenicity to surrounding infrahyoid or strap muscles rather than normal thyroid tissue. This feature is suggestive of increased risk of malignancy and is distinguished from an anechoic or cystic nodule that does not have any reflective solid tissue, and is a benign finding.

\section{Calcification}

Reported as microcalcification, coarse calcification, or rim calcification (Figure 1). Microcalcifications imply the presence of psammoma bodies, measuring 10-100 micron round, and are the most specific feature of thyroid malignancy with a specificity of up to $95 \%$ and positive predictive value ranging from $42-94 \%{ }^{17-19}$ Coarse calcifications, typically causing posterior acoustic shadowing, are more benign features, but may be associated with medullary thyroid carcinoma. ${ }^{20}$ Rim calcification, also reported as peripheral calcification, are bright echoes found on the surface of the thyroid nodule and may represent malignancy. ${ }^{21}$

\section{Margins}

Nodule contour defines its margins. An ill-defined nodule is one in which more than $50 \%$ cannot be clearly demarcated and should not be confused with irregular, lobulated, or jagged margins (Figure 1). A recent study of 1,851 nodules, reported that irregular margins have a specificity for malignancy of around 83\%. ${ }^{22}$ A 2014 meta-analysis noted that irregular margins have an odds ratio of 6.12 for malignancy. ${ }^{23}$ Sharp borders or well-demarcated margins may represent a more benign finding. ${ }^{24}$

\section{Vascularity}

Color Doppler evaluates vascular flow within a nodule and has been proposed as an important component in nodular evaluation. Vascular patterns should be reported as peripheral, intranodular, or avascular. While some studies suggest value to vascularity, others refute this, suggesting it is a poor predictor of malignancy. ${ }^{25-27}$ Much of the debate, for example, is that, while benign nodules possess a predominant peripheral flow pattern, up to $20 \%$ of malignant nodules also have a peripheral pattern. ${ }^{19}$ While the debate continues, reporting vascular flow remains an important component of thyroid ultrasound reporting.

\section{Size}

Nodules are typically measured on three different axis planes (anteriorposterior, transverse, and longitudinal). While identifying malignancy is important, a key feature is to improve survival and minimize tumor burden. Miyauchi and colleagues, monitored $>1,200$ nodules with papillary thyroid carcinoma not removed surgically measuring, $<1.0 \mathrm{~cm} .{ }^{28,29}$ Ten years after serial ultrasounds, known as "active surveillance," $8 \%$ of the nodules grew by $\geq 3 \mathrm{~mm}$ and $3.8 \%$ showed novel appearance of node metastasis without any increased risk of death over the 10-year period. Another study suggests that increasing tumor size beyond $1.0 \mathrm{~cm}$ does not affect survival until a threshold of $2.5 \mathrm{~cm} .{ }^{30}$ Risk of malignancy, based on size, increases as the nodule grows beyond $1.0 \mathrm{~cm}$ with a threshold detected at $2.0 \mathrm{~cm}$, beyond which, cancer risk remains essentially unchanged (e.g., a $3.0 \mathrm{~cm}$ nodule has essentially the same risk of being malignant as a $4.0 \mathrm{~cm}$ nodule). ${ }^{31}$

\section{American Association of Clinical Endocrinologist, American College of Endocrinology, and Associazione Medici Endocrinologi guidelines}

In their most recent update in 2016, the AACE/ACE/AME expanded on their three-class system to better identify the risk of malignancy of thyroid nodules (Table 1). ${ }^{32}$ The risk categories are:

Class 1 (low-risk lesions): These nodules have a risk of malignancy of around $1 \%$ and do not require fine needle aspiration (FNA). ${ }^{33}$ These nodules, made up of pure cysts, or predominantly cystic nodules (>50\% fluid component), are not associated with suspicious ultrasound features. spongiform nodules are also categorized in this group, composed of multiple microcystic spaces separated by thin echogenic septa. ${ }^{34}$ These nodules do not require FNA unless $>2.0 \mathrm{~cm}$ and growing in size.

Class 2 (intermediate-risk lesion): Nodules in this category have a 5-15\% risk of malignancy. These are slightly hypoechoic or isoechoic nodules with an ovoid (wider-than-tall) feature with smooth or ill-defined margins. These lesions may have intranodular vascularity, macro- or continuous-rim calcifications and/or indeterminate hyperechoic foci. Indication for FNA are nodules that are $>2.0 \mathrm{~cm}$.

Class 3 (high-risk lesion): These have at least one of the following features: Marked hypoechogenicity; speculated or lobulated margins; microcalcifications; taller-than-wide shape, show extrathyroidal growth; and/or possess pathological appearing adenopathy. These nodules carry a 50-90\% risk of malignancy depending on how many of these features are present. Nodules in this category should undergo FNA biopsy if $>1.0 \mathrm{~cm}$ while those between 5-10mm may undergo active surveillance and monitoring.

\section{American Thyroid Association guidelines}

In 2015, the ATA developed a five-classification system (benign, very low suspicion, low suspicion, intermediate suspicion, high suspicion) to 
Table 1: American Association of Clinical Endocrinologist/Associazione Medici Endocrinologi thyroid ultrasound features and risk of malignancy ${ }^{32}$

\begin{tabular}{|l|l|l|l|}
\hline $\begin{array}{l}\text { Class } 1 \\
\text { (low risk) }\end{array}$ & Ultrasound features & Risk of malignancy & When to perform FNA \\
\hline $\begin{array}{l}\text { Class } 2 \\
\text { (intermediate risk) }\end{array}$ & $\begin{array}{l}\text { Slightly hypoechoic or isoechoic; ovoid with smooth or ill-defined margins; } \\
\text { macrocalcifications or continuous rim calcification; intranodular vascularity }\end{array}$ & $5-15 \%$ & $>2.0 \mathrm{~cm}$ and enlarging \\
\hline $\begin{array}{l}\text { Class } 3 \\
\text { (high risk) }\end{array}$ & $\begin{array}{l}\text { Marked hypoechogenicity; spiculated; microcalcification; taller-than-wide shape; } \\
\text { evidence of extrathyroidal growth }\end{array}$ & $50-90 \%$ & $>2.0 \mathrm{~cm}$ \\
\hline
\end{tabular}

FNA = fine needle aspiration

Table 2: American Thyroid Association ultrasonographic features and risks of malignancy ${ }^{33}$

\begin{tabular}{|l|l|l|l|}
\hline & Ultrasound features & Risk of malignancy & \multicolumn{1}{l|}{ When to FNA } \\
\hline Benign & Cystic & $<1 \%$ & No biopsy \\
\hline Very low suspicion & Isoechoic/hyperechoic without microcalcifications; regular margins & $<3 \%$ & $>2.0 \mathrm{~cm}$ or observe \\
& & $5-10 \%$ & $\geq 1.5 \mathrm{~cm}$ \\
\hline Low suspicion & Isoechoic/hyperechoic, oval, no microcalcifications & $10-20 \%$ & $\geq 1.0 \mathrm{~cm}$ \\
\hline Intermediate suspicion & Hypoechoic, solid, oval, no microcalcifications & $70-90 \%$ & $\geq 1.0 \mathrm{~cm}$ \\
\hline High suspicion & $\begin{array}{l}\text { Hypoechoic with one or more: +microcalcifications, taller-than-wide, rim } \\
\text { calcification, extrathyroidal extension }\end{array}$ & \\
\hline
\end{tabular}

FNA = fine needle aspiration

identify sonographic features to risk-stratify malignancy risks and assist in determining which nodules require further evaluation with FNA (Table 2). ${ }^{34}$

Benign: These are anechoic/cystic nodules without any solid components. They have a risk of malignancy of $<1 \%$ and typically do not require further workup unless for cosmetic or functional reasons.

Very low suspicion: These nodules have $a<3 \%$ risk of malignancy, and are solid, isoechoic or hyperechoic. They do not have any microcalcifications, irregular margins, or extension into the extrathyroidal space. They are oval (wider-than-tall). Consideration should be made for FNA when the lesion is $\geq 2.0 \mathrm{~cm}$. Observation is also a reasonable option due to its low risk. spongiform or partially cystic nodules are also in this category.

Low suspicion: Isoechoic or hyperechoic solid nodule with or without cystic properties with eccentric solid areas. No microcalcifications or extrathyroidal extension. Nodules may be oval (wider-than-tall). These lesions have a $5-10 \%$ risk of malignancy. FNA is recommended with lesions $\geq 1.5 \mathrm{~cm}$.

Intermediate suspicion: Nodules are hypoechoic, solid, oval (widerthan-tall) and have smooth margins. No microcalcifications are noted. Extrathyroidal extension is not identified. These lesions have a $10-20 \%$ risk of malignancy and FNA is recommended when nodule is $\geq 1.0 \mathrm{~cm}$.

High suspicion: Predominantly solid, hypoechoic containing one or more of the following features: irregular margins (not to be confused with illdefined margins), microcalcifications, taller-than-wide, rim calcification with small extrusive soft tissue components. They may also have evidence of extrathyroidal extension. These lesions have a $>70-90 \%$ risk of malignancy and FNA would be recommended with nodules $\geq 1.0 \mathrm{~cm}$.

\section{The American College of Radiology Thyroid Imaging-Reporting and Data Systems}

In 2012, the ACR developed a reporting system modeled after the their widely accepted Breast Imaging-Reporting Data System, known as BIRADS. ${ }^{35}$ The most recent Thyroid Imaging-Reporting and Data Systems (TIRADS) update in 2017 divides various ultrasound features into five categories assigning points, the total of which determine risk of malignancy and are reported as TR1-5. ${ }^{36}$ The different categories are described in Table 3. Evaluation of the sensitivity, specificity, and accuracy of the TI-RADS system compared to standard thyroid ultrasound evaluation was found to be $87 \%$, $44 \%$, and $52 \%$ respectively. ${ }^{37}$

\section{Comparison between the three societies' reporting systems}

The ultimate goal in the development of thyroid reporting systems is to provide the highest diagnostic accuracy in identifying malignant versus benign thyroid nodules. A recently published cross-sectional study compared the ATA, AACE/ACE/AME, and ACR TI-RADS systems using an automated algorithm to classify each nodule into respective risk categories. ${ }^{14}$ In relation to diagnostic accuracy, no significant difference was seen between the TI-RADS and the AACE/ACE/AME systems $(p=0.287$ ), while the ATA system proved inferior ( $p=0.008$ versus TI-RADS and $p=0.036$ versus AACE/AME). This was not seen in a smaller study of 195 thyroid nodules, which found ATA to have a similar accuracy to TIRADS (60\% for TI-RADS versus $68 \%$ for ATA). ${ }^{15}$ In terms of sensitivity and specificity, when nodules were reported in their highest risk categories, the AACE/ACE/AME system showed high sensitivity with low specificity, while ATA and TI-RADS systems showed high specificity with low sensitivity. ${ }^{14}$ A study evaluating 962 nodules retrospectively reported that specificity of TI-RADS and ATA systems may be influenced by nodular size. ${ }^{38}$ When comparing ATA to TI-RADS, ATA had a higher specificity 
Table 3: The five categories of the Thyroid Imaging-Reporting and Data Systems

\begin{tabular}{|c|c|c|}
\hline Category & Feature (points) & Score \\
\hline Composition & $\begin{array}{l}\text { Cystic (0) } \\
\text { Spongiform (0) } \\
\text { Mixed cystic/solid (1) } \\
\text { Solid or almost completely solid (2) }\end{array}$ & $\begin{array}{l}\text { TR } 1 \text { = } 0 \text { points } \\
\text { Benign } \\
\text { No FNA recommended }\end{array}$ \\
\hline Echogenicity & $\begin{array}{l}\text { Anechoic (0) } \\
\text { Hyperechoic/isoechoic (1) } \\
\text { Hypoechoic (2) } \\
\text { Very hypoechoic (3) }\end{array}$ & $\begin{array}{l}\text { TR2 }=2 \text { points } \\
\text { Not suspicious } \\
\text { No FNA recommended }\end{array}$ \\
\hline Shape & $\begin{array}{l}\text { Wider-than-tall (0) } \\
\text { Taller-than-wide (3) }\end{array}$ & $\begin{array}{l}\text { TR } 3=3 \text { points } \\
\text { Mildly suspicious } \\
\text { Monitor if } \geq 1.5 \mathrm{~cm} \\
\text { FNA if } \geq 2.5 \mathrm{~cm}\end{array}$ \\
\hline Margin & $\begin{array}{l}\text { Smooth (0) } \\
\text { III-defined (0) } \\
\text { Lobulated/irregular (2) } \\
\text { Extrathyroidal extension (3) }\end{array}$ & $\begin{array}{l}\text { TR } 4=4-6 \text { points } \\
\text { Moderately suspicious } \\
\text { Follow if } \geq 1.0 \mathrm{~cm} \\
\text { FNA if } \geq 1.5 \mathrm{~cm}\end{array}$ \\
\hline $\begin{array}{l}\text { Echogenic } \\
\text { foci }\end{array}$ & $\begin{array}{l}\text { None or large comet-tail artifact (0) } \\
\text { Macrocalcification (1) } \\
\text { Rim (peripheral) calcification (2) } \\
\text { Punctate foci (3) }\end{array}$ & $\begin{array}{l}\text { TR } 5 \geq 7 \text { points } \\
\text { Highly suspicious } \\
\text { Follow if } \geq 0.5 \mathrm{~cm} \\
\text { FNA if } \geq 1.0 \mathrm{~cm}\end{array}$ \\
\hline
\end{tabular}

The Thyroid Imaging-Reporting and Data Systems (TI-RADS) assigns points to each of the five categories. Each category sums together to give the risk of malignancy and recommendations for fine needle aspiration (FNA).

(89.8\% versus $80.6 \%$ respectively; $\mathrm{p}=0.003$ ) in nodules $>2.0 \mathrm{~cm}$, while having similar specificity in smaller nodules. ${ }^{38}$ While debate exists as to which system is "better" than the other, it is important to note that thyroid ultrsonography is an evolving field and is far from perfect. For instance, there are occasions in which nodules are considered "unclassifiable" under these systems. Reports suggest that up to $5.0 \%$ in ATA, 3.0\% in TI-RADS, and $2.6 \%$ in AACE/AME fall under this "unclassified" category, ${ }^{1,38}$ of which, malignancy rate reached $38.7 \%$ in TI-RADS group and $28.6 \%$ of the ATA group. ${ }^{38}$ For this reason, further research is needed to improve reporting systems in order to minimize missing possible malignant nodules. Reporting centers should also identify and use the system best suited to the practice. This will help minimize possible reporting errors and allow practitioners a more consistent report.

\section{Ultrasound-guided fine needle aspiration}

Regardless of criteria used to determine the risk of malignancy, FNA is frequently required to cytologically determine if a nodule is malignant. FNA using real time ultrasound is preferred as it allows for a safe, accurate, and cost-effective method for cytologic evaluation..$^{39,40}$ It also helps minimize complications including trauma to nearby vital structures (i.e., carotid artery, trachea, jugular veins). Ultrasound-FNA has an accuracy of $80 \% .{ }^{41}$

\section{Bethesda System for Reporting Thyroid Cytopathology \\ Cytologic diagnosis}

In 2007, the Bethesda System for Reporting Thyroid Cytopathology

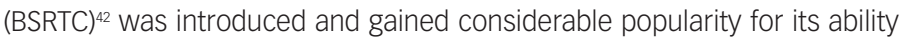
to categorize the risk of malignancy based on cytological evaluation from
Table 4: The Bethesda System for Reporting Thyroid Cytopathology ${ }^{41}$

\begin{tabular}{|l|l|l|l|}
\hline & $\begin{array}{l}\text { Bethesda } \\
\text { category }\end{array}$ & $\begin{array}{l}\text { Risk of } \\
\text { malignancy } \\
\text { pre-NIFTP }\end{array}$ & $\begin{array}{l}\text { Risk of } \\
\text { malignancy } \\
\text { post-NIFTP }\end{array}$ \\
\hline Inadequate/nondiagnostic & I & $5-10 \%$ & $5-10 \%$ \\
\hline Benign & II & $<3 \%$ & $<3 \%$ \\
\hline AUS/FLUS & III & $10-30 \%$ & $6-18 \%$ \\
\hline FN/SFN & IV & $25-40 \%$ & $10-40 \%$ \\
\hline Suspicious for malignancy & V & $50-75 \%$ & $45-60 \%$ \\
\hline Malignant & VI & $97-99 \%$ & $94-96 \%$ \\
\hline
\end{tabular}

The Bethesda System for Reporting Thyroid Cytopathology is divided into six categories (I through VI), listed here with their respective risks of malignancy prior to the reclassification of noninvasive encapsulated follicular variant of papillary thyroid carcinoma to noninvasive follicular thyroid neoplasm with papillary-like nuclear features (NIFTP). AUS = atypia of undetermined significance; FLUS = follicular lesion of undetermined significance; $F N=$ follicular neoplasm; SFN = suspicious for a follicular neoplasm.

FNA samples. ${ }^{43,44}$ This resulted in reduced rates of inappropriate reporting and consequently, fewer surgeries. ${ }^{45}$ The most recent BSRTC publication, in 2017, included several improvements. One of which is the reclassification of noninvasive encapsulated follicular variant of papillary thyroid carcinoma (EFVPTC) to noninvasive follicular thyroid neoplasm with papillary-like nuclear features (NIFTP). ${ }^{42}$ By eliminating the term carcinoma, it reduced patient anxiety by implying a benign condition requiring a more limited follow-up. Another important change in the 2017 BSRTC is the emphasis on the value of molecular testing as an adjunct to cytologic evaluation.

The BSRTC is divided into six tiers (Table 4): I, nondiagnostic; II, benign; III, atypia of undetermined significance (AUS) and follicular lesion of undetermined significance (FLUS); IV, follicular neoplasm (FN) and suspicious for FN (SFN); V, suspicious for malignancy; and VI, malignant. ${ }^{43}$ An important feature of this reporting system is the adequacy of the sample, defined as, no less than six groups of well-preserved thyroid epithelial cells consisting of at least 10 cells in each group. If a sample does not meet these criteria, they are labeled as Bethesda System (BS) I, inadequate or nondiagnostic. Inadequate samples should be correlated with risk stratification based on ultrasound. For example, AACE class 1/ATA benign/or ACR TR1 lesions that are biopsied do not require re-biopsy due to their near negligible risk of malignancy but more suspicious-looking nodules may require repeat biopsy.

\section{The different classifications in the Bethesda System for Reporting Thyroid Cytopathology}

BS II (benign): Cytology reported as benign have a risk of malignancy of $<3 \%$, with a false-negative rate of $1-11 \% .46-48$ False-negative risk tends to increase with nodular size, notably those $>4 \mathrm{~cm}$, suggesting that a re-biopsy may be warranted on larger nodules.9-51 The decision on repeat biopsy is dependent on the correlation between ultrasound features to biopsy report. If discordance between imaging and cytology is noted, repeat FNA is warranted. ${ }^{22.53}$

BS III (AUS/FLUS): These terms are synonyms and not be used to denote two distinct interpretations. Their risk of malignancy is dependent on if the reading pathologist considers NIFTP, the new classification in BS, in the reporting. When the NIFTP category is used, risk of malignancy in AUS/ FLUS is decreased to around 6-18\% compared to the previous $10-30 \%$ risk 
of malignancy. ${ }^{42}$ Thus reducing the implied risk of malignancy in the AUS/ FLUS category. ${ }^{44,54,55}$ Inter-observer and -institutional variability in reporting EFVPTC may alter an organization's reported risk of malignancy ${ }^{56}$ with the biggest impact at centers with high-frequency reporting of EFVPTC. ${ }^{57}$ Management of AUS/FLUS may include, re-biopsy, molecular testing, or lobectomy.

BS IV (FN/SFN): These two terms are synonyms and not used to denote different distinct lesions types. Cibas and Ali report a modest reduction in risk of malignancy reporting from $25-40 \%$ to $10-40 \%$ when reporting the newer benign NIFTP. ${ }^{41}$ since this category maintains a higher risk of malignancy overall but remaining $<50 \%$, management includes molecular testing or lobectomy to confirm malignancy prior to proceeding to total thyroidectomy. This limits post-surgical hypothyroidism in benign nodules. BS V (suspicious for malignancy): Malignancy is suspected on cytology but not with high certainty. ${ }^{42,43}$ Pre-NIFTP, this category carried a $50-75 \%$ risk of malignancy, which has reduced to $45-60 \%$ with the implementation of NIFTP. Papillary thyroid carcinoma dominates this category. Since NIFTP has a more indolent nature, lobectomy is favored over near-total thyroidectomy, when appropriate.

BS VI (malignant): This category carries a high malignancy risk of 9799\%. ${ }^{43}$ Papillary thyroid carcinoma, the most common thyroid cancer, accounts for $70-80 \%$ of the BS VI category. ${ }^{58}$ Cytologically, papillary thyroid carcinoma is characterized by pale chromatin, linear chromatin ridges (grooves), intranuclear cytoplasmic inclusions, and nuclear crowding often overlapping. Medullary thyroid carcinoma, anaplastic carcinoma, lymphomas, poorly differentiated carcinoma, and metastatic cancers are cytologically distinguishable and are also categorized as "malignant".59 Since histological features and cancer type impact treatment, prognosis, and recurrence, they should be reported by the cytopathologist when possible. Near-total thyroidectomy is indicated in this category.

\section{Molecular testing}

Molecular testing, previously difficult to attain due to cost restrictions and availability, now has a higher accuracy, reliability, availability, and affordability, making it easier to attain and interpret. Recommendations suggest use of molecular testing in cytologically indeterminate (BS III/ IV) and sonographically indeterminate nodules to establish better risk of malignancy and indicate whether surgery is indicated. Currently, there are two common molecular tests in clinical use in the United States, Afirma Gene Expression Classifier (GEC; Veracyte South San Francisco, California, USA), established in 2012, ${ }^{60}$ and Thyroseq $^{\circledR}$ V2 (CBLPath, New York, New York, USA), established in 2015..$^{61}$ The 2015 ATA $^{34}$ and 2016 AACE $^{31}$ guidelines recommend consideration of molecular testing for indeterminate nodules (BSRTC III/IV) in establishing risk of malignancy and to determine course of action (surgery versus observation).

The Afirma GEC includes a 142-gene expression molecular assay using microarray to measure mRNA expression in order to classify a nodule as "benign" or "suspicious". The test has a high reported sensitivity (92\%) and negative predictive value (93\%), with a low specificity (52\%) and positive predictive value (47\%), ${ }^{60}$ making this a "rule-out" test for malignancy. Since the reclassification of NIFTP, a decrease in positive predictive value from $42 \%$ to $24 \%$ is seen in the BS III group and from $23 \%$ to $13 \%$ in the BS IV group. ${ }^{62}$ This implies the ability of GEC to better detect carcinoma with EFVPTC, while lower ability to detect carcinoma in the NIFTP category. ${ }^{63}$
Thyroseq V2, designed to identify malignant thyroid nodules using next generation sequencing, detects 14 thyroid cancer-related genetic mutations, including RAS and BRAF mutations, 42 types of gene fusions associated with thyroid cancer, and mRNA expression levels for 16 genes. Thyroseq is reported to have a sensitivity of $90 \%$, specificity of $93 \%$, positive predictive value of $77-83 \%$, and negative predictive value of 96 $97 \%$, with the ability to stratify risk based on the mutation detected..$^{64,65}$ It is considered a test to "rule-in" malignancy. ${ }^{64}$ Since the newer classification of NIFTP, a recent study reports a decrease in positive predictive value with ThyroSeq of $42 \%$ and $33 \%$, respectively when considering NIFTP as malignant or benign.66

BRAFV600E (BRAF) is an amino acid substitution at position 600 in BRAF, found in approximately $45-69 \%$ of all papillary thyroid carcinomas, ${ }^{67}$ with a $100 \%$ specificity for papillary thyroid carcinoma. However, a low overall sensitivity (40-60\%) prevents BRAF from being a valuable screening test alone. ${ }^{68,69}$ In contrast, its presence in a cytologically malignant tumor may predict tumor aggressiveness. ${ }^{70,71}$ by activating various molecular mechanisms, accelerating the tumor's natural course. ${ }^{71}$ In cytological indeterminate nodules (BS III/IV/V), detection of BRAF mutations can improve diagnostic accuracy and reduce unnecessary surgeries. ${ }^{72}$ In NIFTP nodules, BRAF is absent. ${ }^{73}$

The three isoforms of RAS (NRAS, HRAS, KRAS) along with PAX8/PPARG and RET/papillary thyroid carcinoma rearrangements are detected at a lower frequency than BRAF.74 Some evidence suggests that RAS, PAX8/PPARG, or RET/papillary thyroid carcinoma rearrangement-positive nodules may be histologically benign but carry a high potential of becoming malignant, ${ }^{75}$ or are associated with distant metastasis. ${ }^{76}$

\section{Management}

Currently, expert option recommends ultrasound follow-up of nodules in 1-2 years after an initial cytological benign FNA, due to possible initial false-negative aspiration results. Recent studies are beginning to refute this monitoring interval and suggest a longer 2-4-year follow-up interval. ${ }^{77-80} \mathrm{~A}$ recent study of 2,000 cytologically benign nodules noted no long-term sequelae 4 years after initial benign cytology, even if the nodule turned out to have been a false-negative and discovered 4 years after initial biopsy. ${ }^{78}$

A common question, "once a nodule has been re-evaluated, and confirmed to be benign, how long should it be monitored?" There has not yet been a clear census to answer this question. The ATA suggests follow-up with ultrasound every 3-5 years but without a specified endpoint. ${ }^{34} \mathrm{~A}$ recent study suggests that in proven biopsy-negative nodules, consideration should be made to stop monitoring nodules beyond 3 years, as the risk of becoming malignant is exceedingly rare. ${ }^{81}$ In the pediatric population, currently, follow-up ultrasound every 1-2 years is appropriate until further research shows otherwise. ${ }^{82}$ For FNA-benign nodules we prefer repeat ultrasound in 1 year, and periodically thereafter

Historically, thyroxine therapy used to shrink thyroid nodules, was common; typically for cosmetic reasons. This practice typically leads to increased risk of adverse events (i.e., arrhythmia, loss of bone mineral density), ${ }^{83,84}$ along with long-term unnecessary pill use. Since many reports have shown minimal to no efficacy with this practice, ${ }^{85-87}$ the authors feel that the use of thyroxine to shrink nodules should be abandoned. 
While the main focus of this article is the evaluation of thyroid nodules via ultrasound and cytology, we must not forget biochemical testing. Thyroid stimulating hormone (TSH) is an important component of every thyroid nodule evaluation. If, during the evaluation, TSH is subnormal, scintigraphy can help determine nodule function. A hyperfunctional or "hot" nodule is rarely malignant and biopsy is typically not warranted, ${ }^{34}$ thus, eliminating the need for serial ultrasound or FNA. In the case of a multinodular goiter, scintigraphy can separate the "hot" from "cold" (nonfunctional) nodules. This allows the practitioner to focus on the nodules that possess a higher risk of malignancy.

\section{Summary}

The detection of thyroid nodules has increased dramatically over time with the increased use of different imaging modalities. This has also led to a higher incidence/detection of thyroid malignancy. In a patient with normal or elevated TSH, ultrasound remains the method of choice to determine initial risks of malignancy of a thyroid nodule. Oftentimes, poor or incomplete reporting does not allow the practitioner sufficient information to determine if biopsy is indicated leading to overaggressive therapy. The ATA, AACE, and ACR have been standardizing their respective reporting systems to help alleviate this issue. While different from one another, their similar accuracy allows an organization to adopt whichever one best suits their needs.

In 2017, the Bethesda System changed the classification of EFVPTC to NIFTP. While still in its infancy stage, its wide spread use will limit unnecessary surgical procedures and minimize post-surgical hypothyroidism. Molecular testing, previously cost restrictive, has greatly improved the ability to "rulein" (Afirma), or, "rule-out" (ThyroSeq) thyroid malignancy in Bethesda III/ IV nodules. Also, newer recommendations, with their improved accuracy, recommend use of molecular markers in indeterminate nodules to help guide surgical recommendations. $\square$
1. Vander JB, Gaston EA, Dawber TR. The significance of nontoxic thyroid nodules: final report of a 15-year study of the incidence of thyroid malgnancy. Ann Intern Med. 1968;69:537-40.

2. Tunbridge WM, Evered DC, Hall R, et al. The spectrum of thyroid disease in a community: the Whickham survey. Clin Endocrinol (Oxf). 1977;7:481-93

3. Ezzat S, Sarti DA, Cain DR, Braunstein GD. Thyroid incidentalomas. Prevalence by palpation and ultrasonography. Arch Intern Med. 1994;154:1838-40.

4. Hegedüs L. Clinical practice: the thyoid nodule. N Eng/ J Med. 2004:351:1764-71.

5. Guth S, Theune U, Aberle J, et al. Very high prevalence of thyroid nodules detected by high frequency $(13 \mathrm{MHz})$ ultrasound examination. Eur J Clin Invest. 2009;39:699-706.

6. Bartolotta TV, Midiri M, Runza G, et al. Incidentally discovered thyroid nodules: incidence, and greyscale and colour Doppler pattern in an adult population screeed by real-time compound spatial sonography. Radiol Med. 2006:111:989-98.

7. Russ G, Leboulleux S, Leenhardt L, Hegedüs L. Thyroid incidentalomas: epidemiology, risk stratification with ultrasound and workup. Eur Thyroid J. 2014;3:154-63.

8. Yoon DY, Chang SK, Choi CS, et al. The prevalence and significance of incidental thyroid nodules identified on computed tomography. J Comput Assist Tomogr. 2008;32:810-5

9. Nguyen XV, Choudhury KR, Eastwood JD, et al. Incidental thyroid nodules on CT: evaluation of 2 risk categorization methods for work up of nodules. AJNR Am I Neuroradiol. 2013:34:1812-7.

10. Lee $C$, Chalmers B, Treister D, et al. Thyroid lesions visualized on CT: sonographic and pathologic correlation. Acad Radiol. 2015;22:203-9.

11. Noone AM, Howlader N, Krapcho M, et al. SEER Cancer Statistics Review, based on November 2017 SEER data submission, posted to the SEER web site, 2018. Available at: https://seer.cancer.gov/ csr/1975_2015/ (accessed February 17, 2019).

12. National institute of Cancer (NCI). Available at: www.cancer.gov (accessed: April 8, 2019)

13. Symonds CJ, Seal P, Ghaznavi S, et al. Thyroid nodule ultrasound reports in routine clinical practice provide insufficient information to estimate risk of malignancy. Endocrine. 2018;61:303-7.

14. Lauria Pantano A, Maddaloni E, Briganti SI, et al. Differences between ATA, AACE/ACE/AME and ACR TI-RADS ultrasound classifications performance in identifying cytological high-risk thyroid nodules. Eur J Endocrinol. 2018:178:595-603.

15. Macedo BM, Izquierdo RF, Golbert L, Meyer ELS. Reliability of Thyroid Imaging Reporting and Data System (TI-RADS), and ultrasonographic classification of the American Thyroid Association (ATA) in differentiating benign from malignant thyroid nodules. Arch Endocrinol Metab. 2018;62:131-8.

16. Grani G, Lamartina L, Ascoli V, et al. Ultrasonography scoring systems can rule out malignancy in cytologically indeterminate thyroid nodules. Endocrine. 2017;57:256-61.

17. Papini E, Gugliemli R, Bianchini A, et al. Risk of malignancy in nonpalpable thyroid nodules: predictive value of ultrasound and color-Doppler features. J Clin Endocrinol Metab. 2002;87:1941-6.

18. Iannuccilli JD, Cronan JJ, Monchik JM. Risk for malignancy of thyroid nodules as assessed by sonographic criteria: the need for biopsy. I Ultrasound Med. 2004;23:1455-64.

19. Chan BK, Desser TS, MCDougall IR, et al. Common and uncommon sonographic features of papillary thyroid carcinoma. J Ultrasound Med 2003;22:1083-90

20. Zhou L, Chen B, Zhao M, et al. Sonographic features of medullary thyroid carcinomas according to tumor size: comparison with papillary thyroid carcinomas. J Ultrasound Med. 2015;34:1003-9.

21. Yoon DY, Lee JW, Chang SK, et al. Peripheral calcification in thyroid nodules: ultrasonographic features and prediction of malignancy. J Ultrasound Med. 2007;26:1349-55; quiz 1356-7.

22. Remonti LR, Kramer CK, Leitão CB, et al. Thyroid ultrasound features and risk of carcinoma: a systematic review and metaanalysis of observational studies Thyroid. 2015:25:538-50.

23. Campanella P, lanni F, Rota CA, et al. Quantification of cancer risk of each clinical and ultrasonographic suspicious feature of thyroid nodules: a systematic review and meta-analysis. Eur J Endocrino 2014;170:R203-11.

24. Siebert SM, Gomez AJ, Liang T, et al. Diagnostic performance of margin features in thyroid nodules in prediction of malignancy. AJR Am J Roentgenol. 2018:210:860-5.

25. Khadra $\mathrm{H}$, Bakeer $\mathrm{M}$, Hauch $\mathrm{A}$, et al. Is vascular flow a predicto of malignant thyroid nodules? A meta-analysis. Gland Surg. 2016;5:576-82

26. Moon HJ, Kwak JY, Kim MJ, et al. Can vasculartiy at power Dopple US help predict thyroid malignancy? Radiology. 2010;255:260-9.

27. Tamsel S, Demirpolat G, Erdogan M, et al. Power Doppler US pattern of vascularity and spectral Doppler US parameters in predicting malignancy in thyroid nodules. Clin Radio. 2007:62:245-51.

28. Miyauchi $A$, Ito $Y$, Oda $H$. Insights into the management of papillary microcarcinoma of the thyroid. Thyroid. 2018;28:23-31. 29. Miyauchi A. Clinical trials of active surveillance of papillary microcarcinoma of the thyroid. World J Surg. 2016;40:516-22.

30. Nguyen XV, Choudhury RK, Tessler FN, Hoang JK. Effect of tumor size on risk of metastatic disease and survival for thyroid cancer. implications for biopsy guidelines. Thyroid. 2018;28:295-300.

31. Kamran SC, Marqusee E, Kim Ml, et al. Thyroid nodule size and prediction of cancer. J Clin Endocrinol Metab. 2013:98:564-70.

32. Gharib $H$, Papini E, Garber JR, et al. AACE/ACE/AME Task Force on Thyroid. American Association of Clinical Endocrinologists, American College of Endocrinology, and Associazione Medici Endocrinologi medical guidelines for clinical practice for the diagnosis and management of thyroid nodules-2016 update. Endocr Pract. 2016;22:622-39.

33. Kim JY, Jung SL, Kim MK, et al. Differentiation of benign and malignant thyroid nodules based on the proportion of spongelike areas on ultrasonography: imaging-pathologic correlation. Ultrasonography. 2015;34:304-11.

34. Haugen BR, Alexander EK, Bible KC, et al. 2015 American Thyroid Association management guidelines for adult patients with thyroid nodules and differentiated thyroid cancer: the American Thyroid Association guidelines task force on thyroid nodules and differentiated thyroid cancer Thyroid 2016:26:1-133.

35. Spak DA, Plaxco JS, Santiago L, et al. BI-RADS ${ }^{\circledast}$ fifth edition: A summary of changes. Diagn Interv Imaging. 2017;98:179-90.

36. Tessler FN, Middleton WD, Grant EG, et al. ACR thyroid imaging, reporting and data system (TI-RADS): white paper of the ACR TI-RADS committee. J Am Coll Radiol. 2017;14:587-95.

37. Hoang JK, Middleton WD, Farjat AE, et al. Reduction in thyroid nodule biopsies and improved accuracy with American college of Radiology thyroid imaging reporting and data system. Radiology. 2018:287:185-93

38. XU T, GU JY, Ye XH, et al. Thyroid nodule sizes influence the diagnostic performance of TIRADS and ultrasound patterns of 2015 ATA guidelines: a multicenter retrospective study. Sci Rep. 2017;7:43183.

39. Bukjari MH, Niazi S, Hanif G, et al. An updated audit of fine needle aspiration cytology procedure of solitary thyroid nodule. Diagn Cytopathol. 2008;36:104-12

40. Lundgren $\mathrm{Cl}$, Zedenius J, Skoog L. Fine needle aspiration biopsy of benign thyroid nodules: an evidence-based review. World I surg. 2008:32:1247-52.

41. Izquierdo R, Arekat MR, Knudson PE, et al. Comparison of palpation-guided versus ultrasound-guided fine-needle aspiration biopsies of thyroid nodules in an outpatient endocrinology practice. Endocr Pract. 2006;12:609-14.

42. Cibas ES, Ali SZ. The 2017 Bethesda System for Reporting Thyroid Cytopathology. Thyroid. 2017;27:1341-6.
43. Cibas ES, Ali SZ. NCI Thyroid FNA State of the Science Conference. The Bethesda system for reporting thyroid cytopathology. Am J Clin Pathol. 2009:132:658-65

44. Liu X, Medici M, Kwong N, et al. Bethesda categorization of thyroid nodule cytology and prediction of thyroid cancer type and prognosis. Thyroid. 2016;26:256-61.

45. Lau RP, Paulsen JD, Brandler TC, et al. Impact of the reclassification of "noninvasive encapsulated follicular variant of papillary thyroid carcinoma" to "noninvasive follicular thyroid neoplasm with papillary-like nuclear features" on the Bethesda system for reporting thyroid cytopathology: a large academic institution's experience. Am J Clin Pathol. 2017;149:50-4.

46. Redman R, Zalaznick H, Mazzaferri EL, Massoll NA. The impact of assessing specimen adequacy and number of needle passes for fine-needle aspiration biopsy of thyroid nodules. Thyroid. 2006;16:55-60

47. Kuru B, Gulcelik NE, Gulcelik MA, Dincer $H$. The false-negative rate of fine-needle aspiration cytology for diagnosing thyroid carcinoma in thyroid nodules. Langenbecks Arch Surg. 2010;395:127-32.

48. Giles WH, Maclellan RA, Gawande AA, et al. False negative cytology in large thyroid nodules. Ann Surg Oncol. 2015;22:152-7.

49. Koo DH, Song K, Kwon H, et al. Does tumor size influence the diagnostic accuracy of ultrasound-guided fine-needle aspiration cytology for thyroid nodules? Int J Endocrinol. 2016;2016:3803647.

50. Megwalu UC. Risk of malignancy in thyroid nodules $4 \mathrm{~cm}$ or larger. Endocrinol Metab (Seoul). 2017:32:77-82.

51. Castro MR, Gharib H. Thyroid fine needle aspiration biopsy: progress, practice, and pitfalls. Endocr Pract. 2003;9:128-36.

52. Hwang SH, Sung JM, Kim EK, et al. Imaging-cytology correlation of thyroid nodules with initially benign cytology. Int J Endocrino . 2014;2014:491508

53. Rosário PW, Calsolari MR. What is the best criterion for repetition of fine-needle aspiration in thyroid nodules with initially benign cytology? Thyroid. 2015:25:1115-20.

54. Li W, Sciallis A, Lew M, et al. Implementing noninvasive follicular thyroid neoplasm with papillary-like nuclear features may potentially impact the risk of malignancy for thyroid nodules categorized as AUS/FLUS and FN/SFN. Diagn Cytopathol. 2018;46:148-53

55. Faquin WC, Wong $L Q$, Afrogheh $A H$, et al. Impact of reclassifying noninvasive follicular variant of papillary thyroid carcinoma on the risk of malignancy in the Bethesda system for reporting thyroid cytopathology. Cancer Cytopathol. 2016;124:181-7.

56. Zhou H, Baloch ZW, Nayar R, et al. Noninvasive follicular thyroid neoplasm with papillary-like nuclear features (NIFTP): Implications for the risk of malignancy (ROM) in the Bethesda System for Reporting Thyroid Cytopathology (TBSRTC). Cancer Cytopathol. 2018;126:20-6

57. Amendoeira I, Maia T, Sobrinho-Simões M. Non-invasive follicular thyroid neoplasm with papillary-like nuclear features (NIFTP): impact on the reclassification of thyroid nodules. Endocr Relat Cancer. 2018;25:R247-58

58. Aschedbrook-Kilfoy B, Schechter RB, Shih YC, et al. The clinical and economic burden of a sustained increase in thyroid cancer incidence. Cancer Epidemiol Biomarkers Prev. 2013;22:1252-9.

59. Gharib H, Papini E. Thyroid nodules: clinical importance, assessment, and treatment. Endocrinol Metab Clin North Am. 2007;36:707-35

60. Alexander EK, Kennedy GC, Baloch ZW, et al. Preoperative diagnosis of benign thyroid nodules with indeterminate cytology. N Eng/ J Med. 2012;367:705-15.

61. Nikiforov YE, Carty SE, Chiosea SI, et al. Impact of the multi-gene ThyroSeqnext-generation sequencing assay on cancer diagnosis in thyroid nodules with atypia of undetermined significance/ follicular lesion of undetermined significance cytology. Thyroid 2015;25:1217-23. 
62. Hang JF, Westra WH, Cooper DS, Ali SZ. The impact of noninvasive follicular thyroid neoplasm with papillary-like nuclear features on the performance of the Afirma gene expression classifier. Cancer Cytopathol. 2017;125:683-91.

63. Wong KS, Angell TE, Strickland KC, et al. Noninvasive follicular variant of papillary thyroid carcinoma and the Afirma geneexpression classifier. Thyroid. 2016;26:911-5.

64. Sahli ZT, Smith PW, Umbricht CB, Zeiger MA. Preoperative molecular markers in thyroid nodules. Front Endocrinol (Lausanne). 2018;9:179.

65. Nikiforov YE, Carty SE, Chiosea SI, et al. Highly accurate diagnosis of cancer in thyroid nodules with follicular neoplasm/suspicious for a follicular neoplasm cytology by ThyroSeq 22 next-generation sequencing assay. Cancer. 2014:120:3627-34.

66. Valderrabano $P$, Khazai L, Leon ME, et al. Evaluation of ThyroSeg v2 performance in thyroid nodules with indeterminate cytology. Endocr Relat Cancer. 2017;24:127-36.

67. Yarchoan M, LiVolsi VA, Brose MS. BRAF mutation and thyroid cancer recurrence. J Clin Oncol. 2015;33:7-8.

68. Jinih M, Foley N, Osho O, et al. BRAF V600E mutation as a predictor of thyroid malignancy in indeterminate nodules: A systematic review and meta-analysis. Eur I Surg Oncol. 2017:43:1219-27.

69. Pusztaszeri MP, Krane JF, Faquin WC. BRAF testing and thyroid FNA. Cancer Cytopathol. 2015;123:689-95.

70. Xing $M$, Westra WH, Tufano RP, et al. BRAF mutation predicts a poorer clinical prognosis for papillary thyroid cancer. J Clin
Endocrinol Metab. 2005;90:6373-9.

71. Xing M, Alzahrani AS, Carson KA, et al. Association between BRA V600E mutation and mortality in patients with papillary thyroid cancer. JAMA. 2013;309:1493-501.

72. Beiša A, Kvietkauskas M, Beiša V, et al. Significance of BRAF V600E mutation and cytomorphological features for the optimization of papillary thyroid cancer diagnostics in cytologically indeterminate thyroid nodules. Exp Clin Endocrinol Diabetes. 2018; doi: 10.1055/a-0588-4885. [Epub ahead of print].

73. Ferris RL, Nikiforov Y, Terris D, et al. AHNS Series: Do you know your guidelines? AHNS Endocrine Section Consensus Statement: State-of-the-art thyroid surgical recommendations in the era of noninvasive follicular thyroid neoplasm with papillary-like nuclear features. Head Neck. 2018:40:1881-8.

74. Duick, DS. Overview of molecular biomarkers for enhancing the management of cytologically indeterminate thyroid nodules and thyroid cancer. Endocr Pract. 2012;18:611-5.

75. Fukahori M, Yoshida A, Hayashi $\mathrm{H}$, et al. The associations between RAS mutations and clinical characteristics in follicular thyroid tumors: new insights from a single center and a large patient cohort. Thyroid. 2012;22:683-9.

76. Jang EK, Song DE, Sim SY, et al. NRAS codon 61 mutation is associated with distant metastasis in patients with follicular thyroid carcinoma. Thyroid. 2014;24:1275-81.

77. Durante $\mathrm{C}$, Costante $\mathrm{G}$, Lucisano $\mathrm{G}$, et al. The natural history of benign thyroid nodules. JAMA. 2015;313:926-35.

78. Nou E, Kwong N, Alexander LK, et al. Determination of the optimal time interval for repeat evaluation after a benign thyroid nodule aspiration. J Clin Endocrinol Metab. 2014;99:510-6.

79. Medici M, Liu X, Kwong N, et al. Long- versus short-interval followup of cytologically benign thyroid nodules: a prospective cohort study. BMC Med. 2016:14:11

80. Ajmal S, Rapoport S, Ramirez Batlle H, Mazzaglia PJ. The natural history of the benign thyroid nodule: what is the appropriate follow-up strategy? J Am Coll Surg. 2015;220:987-92.

81. Lee S, Skelton TS, Zheng F, et al. The biopsy-proven benign thyroid nodule: is long-term follow-up necessary? J Am Coll surg 2013;217:81-8.

82. Cherella CE, Feldman $\mathrm{HA}$, Hollowell $\mathrm{M}$, et al. Natural history and outcomes of cytologically benign thyroid nodules in children. $J$ Clin Endocrinol Metab. 2018:103:3557-65.

83. Petersen P. Hansen JM. Stroke in thyrotoxicosis with atria fibrillation. Stroke. 1988;19:15-8.

84. Baqi L, Payer J, Killinger Z, et al. Thyrotropin versus thyroid hormone in regulating bone density and turnover in premenopausal women. Endocr Regul. 2010;44:57-63.

85. Bandeira-Echtler E, Bergerhoff K, Richter B. Levothyroxine or minimally invasive therapies for benign thyroid nodules. Cochrane Database Syst Rev. 2014;(6):CD004098.

86. Gharib H, Mazzaferri EL. Thyroxine suppressive therapy in patients with nodular thyroid disease. Ann Intern Med 1998:128:386-94.

87. Castro MR, Caraballo PJ, Morris JC. Effectiveness of thyroid hormone suppressive therapy in benign solitary thyroid nodules: a meta-analysis. J Clin Endocrinol Metab. 2002;87:4154-9. 